\title{
Relevance of Prevention of Postoperative Refluxes
}

\section{Kolchin Dmitry Germanovich ${ }^{1}$, Rulev Vitaliy Nikolaevich ${ }^{2}$, Trukhalev Vadim Aleksandrovich ${ }^{3}$, Kurilov Vadim Aleksandrovich ${ }^{4}$, Martynov Vladimir Leonidovich ${ }^{*}$}

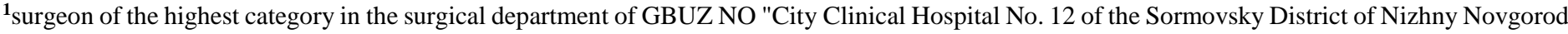

${ }^{2}$ Candidate of Medical Sciences, Head of the Surgical Department of GBUZ NO "City Clinical Hospital No. 12 of the Sormovsky District of Nizhny Novgorod

${ }^{3}$ Candidate of Medical Sciences, Deputy Chief Physician for Surgery, GBUZ NO GKB No. 12 of the Sormovsky District of Nizhny Novgorod

${ }^{4}$ surgeon of the 1st category of the surgical department of GBUZ NO "City Clinical Hospital No. 12 of the Sormovsky District of Nizhny Novgorod

*Corresponding Author: Martynov Vladimir Leonidovich, associate professor, consultant of surgical unit of "GBUZ NO" GKB No. 12 of Sormovsky district of Nizhny Novgorod, Russia.

\section{Received Date: November 15, 2021; Accepted Date: December 22 2021; Published Date: January 12, 2022}

Citation: Kolchin D. Germanovich, Rulev V. Nikolaevich, Trukhalev V. Aleksandrovich, Kurilov V. Aleksandrovich , Martynov V. Leonidovich (2022) Relevance of Prevention of Postoperative Refluxes. J. Gastroenterology Pancreatology and Hepatobilary Disorders 6(2) DOI:10.31579/2641$5194 / 056$

Copyright: (C) 2022, Martynov Vladimir Leonidovich, This is an open access article distributed under the Creative Commons Attribution License, which permits unrestricted use, distribution, and reproduction in any medium, provided the original work is properly cited.

Abstract: Gastrectomy is a complex operation for stomach diseases. Despite the successes to date, there are still no cardinal grounds to recognize the results of gastrectomy as satisfactory (Ruchkin D.V., 2019;

Key words: postgastrectomy complications; apostolos; bile salts; trypsin; lysolecithin

Functional complications after gastrectomy: state and development of the problem.

Yang Y.S. et al., 2013). So the median survival of these patients was 29.3 months, the overall and relapse-free 2-year survival was $74.4 \%$ and $69.5 \%$, respectively (Moon D.H., 2017). However, in the absence of damage to regional lymph nodes, the three-year survival rate is more than 60\% (Roman L.D., 2016).

After gastrectomy, new anatomical conditions are formed. In this case, both trunks of the vagus nerve, including motor, sensory and parasympathetic nerve fibers, are crossed, denervation of the gallbladder occurs, leading to the development of its motor dysfunction, exclusion from the digestive process, stagnation of bile and the formation of calculi, after lymphadenectomy, lymphatic drainage in the upper floor of the abdominal cavity is disturbed, elements of the celiac plexus, including sensory, parasympathetic and postganglionic sympathetic fibers, are injured or completely excised (Chaika A.V. et al., 2018; Chen X. et al., 2014; Ballas KD et al., 2015), various variants of mechanical intestinal obstruction in the form of torsion of intestinal loops or mesenteries, adhesions.

As a result, the components of intestinal contents - bile salts, trypsin, lysolecithin - enter the esophagus, which leads to the development of reflux esophagitis of varying severity (catarrhal, erosive), and in some cases to the emergence of Barrett's esophagus. The pathogenesis of the disease includes the direct damaging effect of these components of the esophageal mucosa (Tarbaev I.S., 2018) and depends on the duration and frequency of reflux (Bax D., 2007).

Gastrectomy in various modifications inevitably contributes to the occurrence of reflux esophagitis (Gumerov A.A., 2020; Xiong J.J. et al., 2013, Bogopol'skij P.M., 2014), which is manifested by the main clinical symptom - heartburn. Reflux esophagitis is an optional precancerous disease that can transform into adenocarcinoma of the esophagus (Korochanskaya N.V. et al., 2017)

Postgastrectomy complications occur in $30-86 \%$ of patients: dumping syndrome (14-82\%), agastral asthenia (30-40\%), hypoglycemic syndrome (7-13\%), reflux esophagitis (7-18\%), syndrome adductor gut $(3.5-16 \%)$, stricture $(3-7 \%)$ of the esophageal-intestinal anastomosis (Ishizuka M. et al., 2014).

To reduce the severity of postgastrectomy complications, more than 70 modifications of gastroplasty options have been developed, which can be conditionally divided into methods with the inclusion of 12-PC in the passage of food intake and without it. Such a large selection indicates a lack of unity of views, as well as unsatisfactory functional results of the proposed methods (Baryshev A.G. et al., 2018; Ruchkn D.V. et al., 2019; Analatos, Apostolos et all., 2018). Currently, at a fundamentally new stage of technological progress, surgeons are faced with the task of not only the technical perfection of the surgical procedure, but also the creation of favorable conditions in the body for compensating for digestion and improving the quality of life of operated patients (D.V. Ruchkin et al., 2019; Banki F . et all., 2017; Wilshire CL, et all., 2016). It 
was found that one of the reasons for the dysfunction of the digestive system after gastrectomy is the rapid passage of food in the jejunum (Baryshev A.G. et al., 2018). In patients without severe concomitant diseases with a low prevalence of the tumor process, the absence of 12PC pathology, to improve functional results, it is recommended to use more physiological reconstruction techniques - according to the $\mathrm{Ru}$ method or jejunogastroplasty options (Chernyavsky A.A. et al., 2016; Sylvia, van der Horst, 2018).

The formation of the esophageal-intestinal anastomosis is the most crucial stage of the operation (Bazaev, A.A. et al., 2016), but their creation requires areflux, which helps to reduce the frequency and severity of manifestations of inflammation, but over time, its valve function weakens or cicatricial anastomotic stricture (Wang JD, 2016). In the absence of a sphincter, reflux occurs, and patients complain of heartburn, belching, regurgitation of food eaten (Ivashkin V.T. et al., 2019).

Vinnik Yu.A. et al. (2013) attach great importance to the blood supply of the intestinal area allocated for anastomosis with the esophagus. In their opinion, the Roux method is advisable to use with insufficient length of the intestinal mesentery, loose type of blood supply and insufficient local blood flow of the graft, which was mainly used after resection of the esophagus in the thoracic region (10\% of observations). In $7.5 \%$ of cases with a short mesentery length, the technique of lengthening it by $4-5 \mathrm{~cm}$ by ligating 1 - 2 radial vessels was used, which made it possible to form an anastomosis without tension not only in the abdominal cavity, but also in the chest, giving preference to the manual method. With the loop reconstruction, the leakage of the esophageal-intestinal anastomosis was observed in $1.3 \%$ of patients, with the reconstruction by the Roux method - in $7.4 \%$ (Aliev S.A. et al., 2015).

Disorders of the motor function of the digestive system are the leading pathogenetic link in the development of many gastroenterological diseases (Trukhmanov A.S., Ivashkina N.Yu., 2019).

Thus, when performing gastrectomy in $31-96 \%$, conditions are created for the occurrence of such a severe functional pathology as reflux esophagitis, leading in almost $25 \%$ of cases to permanent disability of patients (Rybachkov V.V. et al., 2016; Ahmadi N. , 2017).

Prevention of functional disorders after gastrectomy is assessed as an exceptional parameter for improving the quality of life of patients who have undergone an already complex surgical intervention (Gorchakova A., 2017; Yates R. B. et al., 2017).

The results obtained after gastrectomy are not always satisfactory, therefore, the search continues for a technique that will help to avoid or reduce mortality, the number of complications both in the early and late postoperative period, which prompts surgeons to develop new standards in the treatment of this disease (Arutyunyan K.V. et al. ., 2018).

The true prevalence of GERD is also important, which significantly exceeds the indicators of population studies, which do not include individuals with asymptomatic course or atypical (extraesophageal) manifestations of the disease, which affects oncoetiopathogenesis in the esophagus (Ivashkin V.T. et al., 2017; Hunt R. et al., 2018;). The most sensitive and accurate method for determining the functional state of the esophageal-gastric junction is high-resolution manometry (Van Hoeij FB, Bredenoord AJ., 2016).

As indications for surgical treatment of GERD, the development of the disease against the background of hernia of the esophageal opening and the ineffectiveness (intolerance) of drug therapy, which is noted in 10-
$15 \%$ of patients with GERD, are considered (Broeders J. A. et al., 2013; Kohn G. P., 2018). Reflux esophagitis is one of the most common and socially significant chronic diseases, which leads to a significant violation of the quality of life of patients. In $94 \%$ of patients in the long-term period, a positive result from the performed antireflux operations was demonstrated (Chernousov A.F., 2017; Bell R. C. W. et al., 2014). But a few years later, a wave of first failures and complications of antireflux interventions began. The unsatisfactory results of operations are, according to various authors, 6-25.7\% (Durleshter V.M., 2019).

Currently, at a fundamentally new stage of technological progress, surgeons are faced with the task of not only the technical perfection of the surgical procedure, but also the creation of favorable conditions in the body for compensating digestion and improving the quality of life of operated patients.

\section{Gastroenteroanastomosis problems}

After distal resection of the stomach, the surgeon solves an important problem - carrying out a reconstructive stage (the formation of an anastomosis between the stump of the stomach and the small intestine). More than 100 variants of gastroenteroanastomosis have been described, their number is constantly growing, and the incidence of functional and organic post-gastro-resection disorders is, nevertheless, 15-65\% (Fedorov I.V., 2015). The Billroth-2 method allows avoiding collisions in the detection of pronounced cicatricial-ulcerative deformity of the 12-PC bulb, although the Billroth-1 method determines low mortality rates (0.2 - 3\%), on average 1 -2\% (Ruchkin D.V., 2019; Tanaka S. et al, 2011).

Comparative analysis of the clinical and endoscopic picture of gastroesophageal reflux (GER) after resection of the stomach according to Billroth-2 in various modifications revealed significant differences. The manifestations of GER were observed much more often in patients who underwent resection in the modification according to Hofmeister Finsterer (85\%), since during the formation of gastroenteroanastomosis according to this technique, a wide anastomosis is formed, which gapes at the time of the passage of the peristaltic wave, unregulated reflux of intestinal contents from the adductor loop to a gastric stump, which contributes to the development of post-gastro-resection syndromes: reflux gastritis in $75-100 \%$, reflux esophagitis - in 20 - 50\%, dumping syndrome - in 20 - 30\% of patients (Bashirov S.R. et al., 2017; Chernousov A.F. et al., 2016).

When resecting the stomach with the imposition of an areflux anastomosis, an artificial pulp or valve is created, which closes and functions as a gatekeeper and thereby prevents the reflux of duodenal contents into the stomach stump in $40 \%$ of patients (Antonyan S.V. et al., 2017; Chernousov A.F. et al., 2020).

The incidence of erosive reflux gastritis after distal gastric resection in modification B-1 was 28\%, and according to Namikawa T. (2011) even $100 \%$, but the preservation of the pylorus helps to prevent this process to some extent. Up to $17.8 \%$ of reflux gastritis also occurs after distal subtotal gastric resection according to B-2, especially when performing loop plastic surgery (Namikawa T. Et al., 2011).

In persons who underwent gastric resection according to Billroth - 2, all examined had chronic gastritis of varying degrees of activity. It has been demonstrated that the etiological basis of chronic gastritis after gastric resection is mutually reinforcing factors: bile reflux, absence of a gastrinproducing zone (Korochanskaya N.V. et al., 2017). 
Against the background of GHD, a direct correlation was revealed between the combination of the frequency of gastritis and cancer of the body and the upper third of the stomach, erosions and acute ulcers in the body of the stomach, cancer of the distal stomach and mucosal hyperplasia, signs of intestinal metaplasia (Mikhailusov et al., 2018; Tolone S. et al., 2016).

The risk of developing cancer of the gastric stump against the background of GHD with an increase in the postoperative period after resection according to Billroth-2 increases to $22.1 \%$ (Krivigina E.V. et al., 2015).

It should be emphasized that interintestinal anastomosis during gastric resection according to Balfour reduces the frequency $(30-75 \%)$ and severity of enterogastric reflux in comparison with those using the Hofmeister-Finsterer method, but does not completely prevent it (Birendra K. et all., 2009).

There is an opinion that the only variant of gastroenteroanastomosis that can prevent enterogastric biliary reflux is an anastomosis on the Ru-loop (Askerkhanov R.G., 2017; Hirao M. et all., 2013). According to A.V. Bazaeva et al. (2016) gastric resection according to Roux is not inferior in terms of the functional results of gastric resection according to Billroth1 , and in terms of such indicators as the quality of life and the incidence of diseases of the operated stomach, it exceeds the resection of the stomach according to Billroth-2 in the modification of HofmeisterFinsterer and according to Billroth- 1. Although Namikawa T. et all. (2011) Tanaka S. et all. (2011) did not note a significant difference in the two groups of patients. The search for operations to prevent biliary reflux continues (Khitaryan A.G. et al., 2019).

\section{Drainage of organs of the pancreatoduodenal zone, extrahepatic bile ducts}

The number of patients with diseases of the organs of the hepatopancreatoduodenal zone, extrahepatic bile ducts increases every year (Okhotnkov O.I., 2018; N.M. Hogan et al, 2016).

With the introduction of minimally invasive technologies, the frequency of damage to the bile ducts during cholecystectomy remains high and does not correlate either with the experience of the operator, or with the duration of the disease, or with the degree of inflammatory changes in the operation area (Korolkov A.Yu., 2018; Viste, A. et al., 2015; GranadosRomero, J. et al., 2016), but depends on the failure to thoroughly dissect tissues in the area of the Calot triangle. (Khalidov O.Kh. et al., 2017).

The widespread introduction of minimally invasive cholecystectomy methods, even in the hands of experienced surgeons (Korolev M.P. et al., 2016; S. Halbert et all., 2016), led to a significant increase in damage to the extrahepatic bile ducts, the frequency of which reaches $3 \%$ (Ivanov S.V., 2018; Okhotnikov O.I., 2016) to 5.5\%, which is at least 2 times more than with open intervention (Maistrenko N.A. et al., 2016).

But, of course, endovideosurgical technologies have clear advantages in the form of a short hospital stay, quick recovery of work capacity and excellent cosmetic results (Rystedt et al, 2016; J. Kohn et all., 2018).

Intraoperative damage to the bile ducts in $93-95 \%$ of cases is the cause of the development of high cicatricial strictures (Vorobey A.V., 2018). It is important to diagnose and correct "fresh" injuries of the bile ducts (Okhotnikov O.I., 2019; Tulin A.I. et al., 2016; Oh CH., 2016).

Postoperative mortality in the treatment of cicatricial strictures reaches 12 - $30 \%$, the frequency of recurrence of strictures is $30 \%$, in reducing the number of which the choice of a method for restoring the passage of bile into the gastrointestinal tract is of no small importance (Markov P.V., 2017; Atavov R.S. et al., 2017; Ankersmit M. et al, 2017). In reconstructive surgery of the extrahepatic bile ducts, it is important to prevent the development of ascending reflux cholangitis (Belokonev V.I. et al., 2016; Rainio et al, 2018). At the same time, in the overwhelming majority of cases, a loop of the small intestine cut out according to Roux is used (Kukosh M.V. et al., 2016; Pugaev A.V. et al., 2018), which is recognized as the "gold standard" (Shevchenko Yu.L. et al., 2015). But they did not completely abandon the loop interintestinal anastomosis according to Brown and the "plug" of A.A. Shalimova (Tokarenko E.V. et al., 2016; Kurbonov K.M., 2017).

The defeat of the pancreas by tumors is growing. In the European Union, pancreatic cancer is the seventh most common cause of death from malignant neoplasms (Shoda $\mathrm{J}$ et al, 2015). Obstructive jaundice is the most frequent manifestation of tumor diseases of this localization and is detected in $50-80 \%$ of patients (Jo J.H. et al, 2017). Despite the development of surgical techniques, the incidence of complications after radical surgery (pancreatoduodenal resection) remains high - 38-52\% (Shamali A, et al., 2017). In case of contraindications to radical surgery in palliative surgery, a biliodigestive anastomosis on the Roux loop is formed (Kim SY et al., 2018), but the choice of the optimal method of biliary decompression for distal tumor blockade of the bile duct has not yet been fully resolved (Rasulov N.A., 2017).

The question of choosing the optimal and rational therapeutic tactics for cystic pancreatitis is still relevant and one of the most difficult in modern pancreatology (Trace O.N. et al., 2016; Sokolov Yu.Yu.). The presence of intraductal hypertension in chronic pancreatitis in $40-45 \%$, the presence of cysts in a third of patients determines the increasing surgical activity of this pathology, the emergence of new methods of operations. Longitudinal pancreatojejunostomy is considered the "gold standard" of surgical treatment of chronic pancreatitis: on a Brown loop (Dryazhenkov G.I. et al., 2016), with a plug on the adductor loop, or according to the $\mathrm{Ru}$ method (Mukhin A.S., 2016; Chu YC, 2008).

According to published data, of all cystodigestive anastomoses, preference is given to the formation of an anastomosis with the jejunum on a disconnected loop along Roux (Mukhin A.S., 2016; Sarvanov A.V., 2017; Markov P.V., 2017), on the loop of the jejunum with interintestinal anastomosis according to Brown and with the formation of a "plug" according to A.A. Shalimov Stepan E.V. et al., 2017).

But the imposition of a cystopancreatojejunostomy with a completely non-disconnected intestinal loop is unacceptable (Poluektov V.L. et al., 2016), which increases the risk of infection of the cyst cavity, progression of pancreatitis.

Thus, the complexity of early diagnosis and adequate surgical correction, a significant proportion of unsatisfactory results, as well as the low quality of life of patients after unsuccessful reconstructive and restorative surgeries on the extrahepatic bile ducts, pancreatic ducts require the search for new ways to solve the problem (Kozlov I.A., 2017; Benkabbou A. et al. 2013; Addeo P. et al, 2014).

\section{Disadvantages of traditional methods of draining the hollow organs of the abdominal cavity and cavity structures of the retroperitoneal space}

Scarring of formed bile-intestinal anastomoses occurs in $9.8-35 \%$ of cases (Markov P.V., 2017; Benkabbou A. et al., 2013). With repeated operations, the mortality rate was $8.3 \%$, their implementation requires a 
high professionalism of the surgeon and the development of new, more effective methods with the passage of bile into the duodenum (Markov P.V., 2017).

Jejunoanastomosis with interintestinal anastomosis according to Brown does not allow to fully avoid the above complications even when using the "plug" by A. A. Shalimov (Shalimov A.A., 1993), which eventually undergoes recanalization (Atavov R.S. et al., 2017). The authors themselves point to the possible restoration of the patency of the intestinal canal due to bedsore ligatures and metal clips at the site of their imposition. Their intussusception also cannot always reliably prevent the restoration of the intestinal lumen. This outcome does not prevent the ingress of intestinal contents into the drained structures (Atavov R.S. et al., 2017).

According to Belekov Zh.O. et al. (2007) clinical and endoscopic manifestations of reflux esophagitis associated with recanalization of the "Shalimov AA plug" were found in $63.2 \%$ and $58.3 \%$ of patients, respectively. The use of a loop of the small intestine with a Brownian anastomosis for anastomosis with the esophagus after gastrectomy without a plug leads to the development of reflux esophagitis in the first three months after surgery in $90 \%$ of patients (Panibratz L.S., 2010). The use of even two Brownian anastomoses on the loop of the intestine brought into the gates of the liver does not exclude the throwing of intestinal contents into the ducts and, as an outcome, stricture (Dryazhenkov G.I., 2015).

Only sufficient in length, at least $80 \mathrm{~cm}$ according to Aliyev et al., 2015, the abduction segment of the intestine significantly reduces intestinal reflux, which reduces the likelihood of developing ascending cholangitis (Korolev M.P. et al., 2017).

In the European surgical school, preference is given to reconstruction with the Roux-off loop of the jejunum, the length of which should be at least $40 \mathrm{~cm}$ to avoid reflux of bile and intestinal contents into the stomach stump and esophagus (Wirtzfeld D., 2015).

Opponents of the anastomosis on the Roux loop declare the complexity of such operations, are dissatisfied with the exclusion of a significant portion of the small intestine from digestion, note a significant number (2 - 17.6\%) of complications in the form of anastomotic leakage (Abdullaev A.A., 2019; Atavov R.S. ., 2017; Koroleva A.A., 2017; Kuchin D.M., 2017; Kotelnikova L.P., 2020), reflux of intestinal contents remains in the drained structure in $27 \%$ of patients (Kulezneva Yu.V., 2019).

Microcirculatory changes in the wall of the intestinal loop, cut out according to Roux, the intersection of nerve fibers in 9-50\% cause Rouxstasis syndrome (Aujeaky R., et all., 1998; Wei H.B., et all., 2006). The essence of the stasis syndrome is in violation of the patency of the abducting knee of the small intestine in the area before enteroenteroanastomosis in the absence of organic obstacles. The development of this syndrome is due to the isolation of the small intestine pacemaker located in the 12-PC bulb. When a Roux-off loop is formed, it is disconnected from the 12-PC pacemaker; therefore, persistent electrical dysrhythmia of the Roux-loop becomes possible (J. Mathias et al. (1985; Hoya Y. et al, 2009).

G.K. Zherlov et al. (2009) see the main cause of Roustasis syndrome in the negative effect on the efferent gut of the intersection of parasympathetic nerve fibers with preserved sympathetic innervation, impaired blood supply to the ejaculatory loop of the jejunum and impaired evacuation capacity of the gastric stump, and gastric stasis in 5-15\% of patients.
It is also known that in a Roux-mobilized loop of the small intestine more than $40 \mathrm{~cm}$ long, the likelihood of developing a stasis syndrome sharply increases. Therefore, the length of the abducting loop over $40 \mathrm{~cm}$ during Roux-en-route resection is attributed to the main risk factor for the development of stasis syndrome, the optimal length of the loop is considered to be within 35-40 cm (Chernousov A.F., 2008).

Subtotal and total esophagoplasty of the small intestine on a vascular pedicle is now used in exceptional cases, mainly because of the generally recognized unfavorable features of its angioarchitectonics, the features of which do not allow guaranteed blood supply to the graft throughout its entire length. Performing techniques for lengthening the small intestinal loop of Roux requires great care in terms of ensuring vascularization of its ends (Simich P., 1979). At the same time, it was proved that on the intestinal segment without a vascular pedicle and with blood supply only by the marginal arch, its wall, which exceeds the limit of a straight vessel by $1 \mathrm{~cm}$, receives only half of the blood flow that it would receive under normal conditions. When this excess is $2 \mathrm{~cm}$, the gut receives only $1 / 6$ of the blood flow rate. This area of possible vascular risk exists exactly where the loop anastomosis will be performed.

These authors attribute to the disadvantages of the Roux-en-Y anastomosis a higher incidence of cholelithiasis (15-20\% of patients) in the long term after surgery. When choledocholithiasis is detected after Roux-en-route resection, there is also an obvious complexity of endoscopic manipulations on the duodenal papilla, limiting the possibility of performing endoscopic papillotomy and extraction of stones from the common bile duct (Vorobey A.V., 2017). The longer the Ru-loop is, the less likely endoscopic surgery is (Nunobe S., Okaro A., et all., 2007).

Thus, with internal drainage of the hollow organs of the abdominal cavity and cavity formations of the retroperitoneal space, the methods of surgical prevention of postoperative reflux into the drained structures according to the method of A.A. Shalimov are ineffective, and drainage according to Roux's method has its drawbacks, which affect the immediate and late postoperative periods, the development of functional and organic complications, and the quality of life of patients.

After reconstructive operations on the stomach in order to identify gastroesophageal biliary reflux, additional research is carried out, which determines the development of oncopathology of the stomach and esophagus (Salama, TMS et al., 2017; T. Saarinen et al., 2017; M. Bruzzi Chevallier et al., 2017).

Therefore, the development of new approaches to solving these problems is urgent.

\section{Problems of creating nutritional jejunostomy}

Eating disorders in the postoperative period significantly reduce the effectiveness of treatment, increase the risk of developing septic and infectious complications, increase the length of hospital stay, worsen the mortality rates (Zybin K.D., 2017; Rodoman G.V., et al., 2017).

Tumor stenoses and cicatricial strictures of the esophagus lead to obstruction of the proximal parts of the digestive tract with the development of nutritional insufficiency, depletion and extinction of the compensatory capabilities of the body, which causes the refusal of the simultaneous formation of an artificial esophagus in patients of this category. For this category of patients, more and more attention is paid to the use of enteral nutrition for a long time through the areflux stoma (Marco B. et al., 2001), as the most physiological, causing fewer complications and an economically justified method (Nicola W., 2003). 
The incidence of purulent mediasthenitis with esophageal perforation reaches $80 \%$, and the mortality rate is $40-45 \%$. The main task is to stop the flow of the contents of the lumen of the esophagus into the mediastinum, which determines the relevance of a nutritious stoma in these patients (Stolyarov S.I., 2016).

The use of nasointestinal intubation entails formidable complications - the formation of acute gastric ulcers and 12-PC, including those complicated by bleeding. The leading method for preventing such complications is the appointment of proton pump blockers, which leads to a decrease in the production of hydrochloric acid. The negative side of this therapeutic effect is a significant increase in the degree of bacterial contamination of the upper gastrointestinal tract in combination with a change in the microbiological landscape. Under these conditions, the presence of a foreign body (probe) in the esophagus and oropharynx, as well as the impossibility of hermetically closing the esophageal sphincter, create favorable conditions for the translocation of pathogenic microorganisms into the trachea and bronchi. The result of the above pathological processes is an increase in the frequency of nosocomial pneumonia (Yates, R. B. et al., 2017).

In his operating work, the surgeon often uses the patient's tissue to solve practical problems. For our work, the data of Liebermann-Meffert D. and White H. (1989) on the greater omentum are of interest. Research shows that the "policeman of the abdominal cavity" - the great omentum in pathological conditions, acquires very special properties: plasticity; the ability to adhere to an injured and inflamed surface; the ability to hemostasis; the ability for ingrowth and revascularization; the ability to absorb liquids and microparticles from the abdominal cavity; the ability to phagocytosis and immunological response. Adhesions with the omentum are formed much faster than with other organs of the abdominal cavity. Even the freely transplanted omentum tissue without blood supply retains these properties. After 21 days, the omentum tissue is completely fused with the recipient organ (Loewy R., 1996; Thompson S.A., Pollock B., 1945).

Experimental studies on ingrowth of the omentum graft and its vessels are very indicative. Sections of the omentum of various thicknesses and sizes were separated from its bulk and fixed without revascularization to various organs and tissues of the same or another animal: stomach, small and large intestine, liver, spleen, kidney, bladder, lung, pleura, peritoneum, mesentery, aorta, inferior vena cava. Within a week, the graft is firmly attached to the tissues of the recipient organs, its separation is difficult, due to a decrease in the amount of fat, its thickness is reduced, necrobiotic processes and necrosis zones are reduced. After three weeks, the graft cannot be separated, when an attempt is made, bleeding occurs, the amount of fat decreases and is replaced by dense fibro- and angioplastic tissues so that its surface resembles the surface of the recipient tissue. After 12 weeks, it is difficult to distinguish the omentum tissue from the recipient tissue; the suture line serves as a reference point. The engraftment of free grafts did not depend on their size, but necrosis zones are more often formed in thick grafts. The graft remains viable when frozen for two weeks or even longer.

Stages of omentum graft engraftment: attachment - up to 4 hours, beginning of vascular ingrowth - 24 hours, tight fit - 48 hours, revascularization - 3 days, fat resorption - 3 weeks, fibrous degeneration - 24 weeks (Liebermann-Meffert D., White H. , 1989).

Such negative consequences of enterostomy as dehydration, electrolyte disturbances, as well as local parastomal manifestations limit the use of this operation (Ibatullin A.A. et al., 2017). These negative aspects in the formation of an enterostomy can be prevented by forming an areflux (Martynov V.L. et al., 2017) nutritious small intestinal stoma using a "plug".

The question of choosing a method of artificial nutrition for malnourished patients should be reduced to the rule: "If the intestines are working, it should be used" (Mosolkov V.Yu., 2009).

Thus, the development of inflammatory changes as a result of reflux of foreign contents in terms of chemical and bacteriological composition in the drained organs of the abdominal cavity and retroperitoneal space affects both the immediate results of surgery and the further quality of life of patients. Without taking into account the arising refluxes, postoperative reflux disease develops.

The development of measures for the prevention of postoperative reflux disease is an important task of surgical science and practice.

\section{References}

1. Abdullaev, A.A. (2019) Surgical tactics for extrahepatic biliary tract injuries, Bulletin of the Russian Military Medical Academy. No. S1. - S. 15-18.

2. Antonyan, S.V. (2017) Reflux esophagitis in patients after gastric resection, Medical Bulletin of the North Caucasus. No. 2. - S. 141-144.

3. Harutyunyan, K. V. (2018) Surgery of esophageal cancer: past, present, future (scientific review) Preventive and clinical medicine. No. 1 (66). - S. 70-77.

4. Askerkhanov, R.G. (2017) Features of the formation of the proximal anastomosis during bariatric gastrojejuncture according to Ru, Endoscopic surgery. 23. - No. 3. - P. 32-36.

5. Atavov, R.S. (2017) Unsolved problems in the issue of choosing the optimal biliodigestive anastomosis, Medical science and education of the Urals, T. 18. - No. 3 (91). - S. 61-64.

6. Bazaev, AV. (2016) The choice of the method of formation of the esophageal-intestinal anastomosis during gastrectomy, Collection of materials. First Congress of Surgeons of the Volga Federal District (with international participation), Nizhny Novgorod, 2016. Electronic edition.

7. Baryshev, A.G. (2018) Efficiency of processes depending on the method of reconstruction of the digestive system after gastrectomy, Bulletin of surgical gastroenterology. No. 4. - P. 13-14.

8. Bashirov, SR. (2017) Restoration of the obturator mechanism of the cardia during distal resection of the stomach in patients with ulcerative pylorobulbar stenosis and disease of the operated stomach, Questions of reconstructive and plastic surgery. No. 1. - P. 46-52.

9. Belekov, Zh. O. (2007) Assessment of functional results of esophagojejunoanastomoses after gastrectomy, Bulletin of KRSU. T. 7 (No. 6). - S. 158-161.

10. Belokonev, V. I. (2016) The choice of the method of operation in patients with choledocholithiasis that developed after vagotomy and gastric resection operations, Collection of materials. The first congress of surgeons of the Volga Federal District (with international participation), Nizhny Novgorod, Electronic edition.

11. Vinnik, Yu. A. (2013) Reconstructive-restorative stage of gastrectomy for cancer of the proximal stomach, Surgery. No. 12. - P. 11-17. Sparrow, A.V. Stricture of hepaticojejunostomy complicated by intrahepatic cholangiolithiasis, Bulletin of surgery. No. 1-2. - S. 89-93. 
12. Gorchakova A. (2017) GERD palette: various forms, extraesophageal manifestations, combinations with other diseases Effective. pharma-macotherapy. No. 5. - P. 24-33.

13. Gumerov, A.A. (2020) Method for reconstruction of the gastrointestinal tract after gastrectomy in a newborn, No. RU 2713956 C1. Russia. 2020. Application No. 2019110664. Date of registration: 09.04.2019. Date of publication: 11.02.

14. Dryazhenkov, (2016) GI Diagnostics and surgical treatment of chronic pancreatitis as an outcome of an acute process in a general surgery department / GI Dryazhenkov et al. // Collection of materials. First Congress of Surgeons of the Volga Federal District (with international participation), Nizhny Novgorod, Electronic edition

15. Durleshter, V.M. (2019) Features of repeated antireflux interventions bulletin of surgical gastroenterology, Bulletin of surgical gastroenterology. № 1. - P. 21-27.

16. Zherlov, G.K. (2009) Fundamentals of Functional Surgical Gastroenterology gii: A Practical Guide for Physicians. - Tomsk: Publishing house of Vol. University, $274 \mathrm{p}$.

17. Zybin, K.D. (2017) An individual approach to providing nutritional support for patients with acute pancreatitis, Bulletin of surgical gastroenterology. No. 2. - P.28-30.

18. Ibatullin, A. A. (2017) Reconstructive surgery of stomal complications, Medical Bulletin of Bashkortostan. T. 12. - No. 5 (71). - S. 25-32.

19. Ivashkin, VT. (2017) Clinical recommendations of the Russian Gastroenterological Association for the diagnosis and treatment of gastroesophageal reflux disease, Ross. zhurn. gastroenterol. hepatol. coloproctol. No. 27 (4). - S. 75-95.

20. Ivanov, S.V. (2018) Tactics of treatment of iatrogenic lesions and strictures of the extrahepatic biliary tract, Russian medical journal. Medical Review. Volume 2(12). - P. 16-18.

21. Kozlov, I.A. (2017) Surgical treatment of complicated chronic pancreatitis, High-tech medicine. Volume 4(1). - P. 43-55.

22. Korolev, MP. (2016) Combined ante- and retrograde restoration of the continuity of the common hepatic duct after combined iatrogenic injury, Bulletin of surgery. Volume 175(2). -S. 105107.

23. Koroleva, AA. (2017) Diagnostics and choice of a method of surgical treatment of cystic transformations of the bile ducts in adults: diss. Cand. honey. sciences. Moscow, 2017.112 p.

24. Korolkov, A.Yu. (2018) Surgical tactics for cicatricial strictures of the biliary tract as a result of their iatrogenic damage, as well as after restorative operations, Bulletin of surgery. No. 1. - P. 6468.

25. Korochanskaya, N.V. (2017) Reflux esophagitis as a complication of gastrectomy, Scientific Bulletin of Kuban Health. No. 3 (51). - S. 26-34.

26. Kotelnikova, LP. (2020) Results of surgical treatment of extrahepatic bile duct injuries. Perm Medical Journal. 37(1). - P. 63-72.

27. Kukosh, V. M. (2016) The role of optical coherence tomography in determining the length of cicatricial strictures of extrahepatic bile ducts, Collection of materials. The first congress of surgeons of the Volga Federal District (with international participation), Nizhny Novgorod, Electronic edition.

28. Kulezneva, Yu.V. (2019) Experience of using hepatocholescintigraphy in the diagnosis of functional concussion of biliodigestive anastomoses, Annals of Surgical Hepatology, 24(1). - P. 53-60.

29. Kurbonov KM. (2017) Resection and transplant technologies in surgery of high post-traumatic cicatricial strictures of the bile ducts, Annals of surgical hepatology. T. 22.4. - S. 61-65.
30. Kuchin, DM. (2017) Selection of the optimal method for the formation of pancreatodigestive anastomosis in gastropancreatoduodenal resection: diss. Cand. honey. sciences. Moscow, $101 \mathrm{p}$.

31. Liebermann-Meffert, D., White, H. (1989) Big gland: Medicine, $336 \mathrm{p}$.

32. Makarov, IV. (2015) Treatment of patients with obstructive jaundice syndrome, VIII Assumption Readings. Materials of the scientific-practical conference of Russian doctors with international participation, dedicated to the 60th anniversary of the Department of General Surgery, Tver State Medical University. Tver, S. 58-59.

33. Markov, P.V. (2017) Surgical treatment of recurrent benign strictures of biliodigestive and biliary anastomoses, Bulletin of surgical gastroenterology. 4. P. 29-32.

34. Martynov V.L. et al. (2017) Intraoperative prevention and treatment of digestive system refluxes St. Petersburg: "Liteo", 336 p. ISBN978-5-00071-901-5

35. Merzlikin, N. V. (2015) Surgical methods of treatment of patients with formed pancreatic cysts, Bulletin of Siberian Medicine.14(2). - S. 20-28.

36. Mikhailusov, S. V. (2018) Duodenogastric reflux: clinical features, Bulletin of the DSEA. No. 1 (26). - S. 78-84.

37. Mosolkov, V. Yu. (2009) Areflux jejunostoma in surgery of tumor stenosis of the esophagus, Siberian Journal of Oncology. No. 3. - S. 30-35.

38. Mukhin, A. S. (2016) Optimization of surgical tactics in the treatment of pancreatic cysts / A. S. Mukhin, L. A. Otdelnov // Collection of materials. The first congress of surgeons of the Volga Federal District (with international participation), Nizhny Novgorod, Electronic edition ...

39. Okhotnikov, OI. (2016) Interventional radiology in the treatment of strictures of biliodigestive anastomoses, Surgery. No. 5. - S. 37-42.

40. Okhotnikov, O.I. (2018) Iatrogenic damage to the common hepatic duct during laparoscopic cholecystectomy, complicated by the formation of right-sided retroperitoneal biloma, Surgery news. 2(6). - P. 765-771.

41. Okhotnikov, O.I. (2019) X-ray surgical interventions for benign biliary strictures after cholecystectomy, Annals of Surgical Hepatology. 24(1). - S. 83-91.

42. Nurse, LS. (2010) Possibilities of improving the quality of life of patients with post-gastrectomy depending on the option of small bowel plastics: Author's abstract. dis. ... Cand. honey. Sciences, Bishkek. 17 p.

43. Pogodina, AN. (2015) Diagnostics and treatment of purulent mediasthenitis, Almanac of the Institute of Surgery named after A.V. Vishnevsky. No. 2 (1175). - S. 1168.

44. Pogodina, AN, (2015) Surgical treatment of damage to the esophagus, Almanac of the A.V. Vishnevsky. No. 2 (1178). - S. 1171.

45. Poluektov V.L. (2016) Method of surgical treatment of postnecrotic cysts of the pancreas, Bulletin of surgery. 175(2). S. 87-89.

46. Pugaev, A.V. (2018) The influence of the method of decompression of the bile ducts after their damage to the results of recovery operations, Surgery, No. 8. - P. 19-24.

47. Rasulov, N.A. (2017) Optimization of diagnostics and treatment of various types of cicatricial strictures of the bile ducts. Bulletin of the Academy of Medical Sciences of Tajikistan. No. 2 (22). S. 47-50.

48. Repin, M.V. (2016) Aspects of diagnostics and reconstructive surgery of functional disorders of the digestive system, Perm Medical Journal. Issue. 33. - No. 4. - S. 33-42. 
49. Repin, M.V. (2018) The value of connective tissue dysplasia in the origin of arteriomesenteric compression of the duodenum. Perm Medical Journal. 35. - No. 1. - S. 38-46.

50. Rodoman, G. V. (2017) Optimization of early enteral nutritional support after gastrectomy, Surgeon. No. 1. - P. 9-16.

51. Roman, L. D. (2016) Possibilities of surgical treatment of complicated forms of locally advanced cancer of the thoracic esophagus, Preventive and Clinical Medicine. 3. - P. 67-71.

52. Ruchkin, D.V. (2019) Reconstructions of the digestive tract after stomach operations, Surgery. No. 1. - S. 37-46.

53. Ruchkin, D.V. (2019) Reconstructive surgery for recurrent gastric cancer, Oncology. Journal them. P.A. Herzen. 8(5). - S. 340-347.

54. Rybachkov, V.V., Vasin A.B., Malashenko V.N., Dubrovina D.Ye. (2016) Surgical tactics for jejunoesophageal reflux after gastrectomy, Modern problems of science and education. No. 11: 1336.

55. Sarvanov, A. V. (2017) Some reasons for failures in the surgical treatment of iatrogenic damage to the bile ducts, Clinical medicine. S. 58-63.

56. Simich, P. (1979) Bowel surgery. Honey. ed. - in "Bucharest", $399 \mathrm{p}$.

57. Trail, ON. (2016) Surgical treatment of chronic cystic pancreatitis / O.N. Trail et al. // Bulletin of Siberian Medicine. 15(2). - P. 85 - 97.

58. Sokolov, Yu.Yu. (2019) Experience of using laparoscopic interventions in children with pancreatic pseudocysts, Medical almanac. No. 5-6 (61). - S. 22-26.

59. Stepan, E.V. (2017) External pancreatic fistulas - diagnosis and treatment, Bulletin of surgical gastroenterology. No. 4. - S. 3-7.

60. Stolyarov, SI. (2016) Damage to the esophagus by foreign bodies, complicated by mediasthenitis / SI Stolyarov // Collection of materials. The first congress of surgeons of the Volga Federal District (with international participation), Nizhny Novgorod, Electronic edition.

61. Tarbaev, I.S. (2018) Unresolved issues of surgical treatment of gastroesophageal reflux disease, Bulletin of surgery. No. 4. P.97-100.

62. Tokarenko, E.V. (2019) "Fresh" iatrogenic lesions of the extrahepatic bile ducts - a two-stage approach using minimally invasive percutaneous interventions

63. Trukhmanov, A.S. (2019) The clinical significance of disorders of the motor function of the esophagus, stomach and duodenum, Therapeutic archive. No. 8. - P. 127 - 134.

64. Tulin, A.I. (2016) Percutaneous transhepatic drainage with a Yshaped catheter system in recurrent cicatricial strictures of the bile ducts, Ann. Surgeon. Hepatol. No. 21 (4). - S. 47-54.

65. Khalidov, O. Kh. (2017) Damage to the extrahepatic bile ducts during laparoscopic cholecystectomy, Annals of Surgical Hepatology. T. 22. - No. 4. - S. 46-52.

66. Khitaryan, A.G. (2019) Pathomorphological aspects of the development of biliary reflux after mini-gastric bypass, Bulletin of surgery. 178(5). - P. 22-30.

67. Seagull, A.V. (2018) Functional consequences of operations for malignant gastric tumors: prevention, diagnosis and treatment of post-resection disorders. Ros zhurn gastroenterol hepatol coloproctol. No. 28 (3). S. 4-17.

68. Chernousov, AF. (2020) Results of repeated resection of the stomach according to Billroth-1 and organ-preserving operations in the treatment of duodenal ulcer, Surgery news. 28(1). - S. 112119.

69. Chernousov, A. F. (2016) Reconstructive surgery for patients with post-gastro-resection syndromes, Bulletin of surgical gastroenterology. 3. - S. 38-39.
70. Chernousov, A.F. (2017) The quality of life of patients with long-term and complicated reflux esophagitis after surgical treatment, Bulletin of the interethnic center for the study of the quality of life. No. 29-30. - S. 33-42.

71. Chernyavsky, A. A. (2016) Esophageal-intestinal anastomosis and methods of reconstruction after transperitoneal gastrectomy, Bulletin of surgical gastroenterology.. 3. - P. 23.

72. Shalimov, A. A. (1987) Surgery of the digestive tract. Part I: Health, S. 137-156.

73. Shalimov A. A. (1993) Surgery of the liver and bile ducts. Kiev: Health, $512 \mathrm{p}$.

74. Shevchenko Yu. L. (2015) Diagnostics and surgical treatment of iatrogenic lesions of the extrahepatic bile ducts, Almanac of the A.V. Vishnevsky, No. 2 (267). - S. 274-275.

75. Yartsev, P.A. (2017) Method of reconstruction of the gastrointestinal tract in chronic arteriomesenteric compression of the duodenum, Patent No. RU 2607512. Russia. 2017. Application No. 2015137632. date of registration 09/04/2015. Date of publication 01/10/2017.

76. Addeo, P. (2014) Pancreatic fistula after a pancreaticoduodenectomy for ductal adenocarcinoma and its association with morbidity: a multicenter study of the French Surgical Association, HPB (Oxford). 16(1). - P. 46-55.

77. Ahmadi, N. (2017) Impact of surgical approach on perioperative and long-term outcomes following esophagectomy for esophageal cancer, Surg. Endosc.

78. Altieri, M.S. (2018) Increasing bile duct injury and decreasing utilization of intraoperative cholangiogram and common bile duct exploration over 14 years: an analysis of outcomes in New York State, Surgical Endoscopy. No. 32 (2). - R. 667-674.

79. Analatos, Apostolos et al. (2018) Evaluation of resection of the gastroesophageal junction and jejunal interposition (Merendino procedure) as a rescue procedure in patients with a failed redo antireflux procedure. A single-center experience, BMC Surg. No. 18 (1). - P. 70.

80. Ankersmit, M. (2017) Fluorescent imaging with indocyanine green during laparoscopic cholecystectomy in patients at increased risk of dile duct injury, Surgical Innovation. 24 (3). R. 245-252.

81. Aujeaky, R. (1998) Restoration of digestive passage after total gastrectomy, Rozhl. Chir. No. 77 - V. 1. - P. 42-44.

82. Ballas, K.D. (2015) Acute afferent loop syndrome: a true emergency, Acta Chir Belg. No. 109. - P. 101.

83. Banki, F. (2017) Laparoscopic Reoperative Antireflux Surgery Is More Cost-Effective than Open Approach. J Am Coll Surg. No. 225 (2). - R. 235-242.

84. Bax, D. (2007) CDX2 expression in columnar metaplasia of the remnant esophagus in patients who underwent esophagectomy, $J$ Clin Gastroenterol. No. 41 (375-9).

85. Bell, R. C. W. (2014) Univariate and multivariate analyzes of preoperative factors influencing symptomatic outcomes of transoral fundoplication, Surg. Endosc. 28 (10). - R. 2949-2958.

86. Benkabbou, A. (2013) Treatment of failed Roux-en-Y hepaticojejunostomy after post-cholecystectomy bile ducts injuries, Surgery. 153(1). - P. 95-102.

87. Bogopol'skij P.M. (2014) Istorij a rekonstruktivnoj hirurgii pishhevoda v Rossii: avtoref. dis. dok. med. nauk: 07.00.10 / Bogopol'skij Pavel Majorovich. M.

88. In 1948, McManus substantiated the possibility and expediency of a one-time operation, which made this intervention widespread in the fifties of the twentieth century .

89. Broeders, J. A. (2013) Laparoscopic anterior 180-degree versus nissen fundoplication for gastroesophageal reflux disease: 
systematic review and meta-analysis of randomized clinical trials, Ann. Surg. 257. P. 850-859.

90. Bruzzi, M. (2017) One-anastomosis gastric bypass: why biliary reflux remains controversial? Obes. Surg. 27. - No. 54. - P. 545547.

91. Buhl, K. (1995) Reconstruction after gastrectomy and quality of life, Wld. J. Surg. No. 19. - V. 4. - P. 558-564.

92. Chen, X. (2014) Digestive tract reconstruction pattern as a determining factor in postgastr- ectomy quality of life, World $J$ Gastroenterol, No. 7:20 (1). - R. 330-332.

93. Chu, Y. C. (2008) Double-balloon enteroscopy application in biliary tract disease - its therapeutic and diagnosis function, Gastrointest. Endosc. 68(3). - P. 585-591.

94. Granados-Romero, J. J. (2019) Current perspective in the treatment of bile duct injuries. / J. J. Granados-Romero, A. G. Estrada-Mata, M. Espejel-Deloiza et all. // Int. J. Res. Med. Sci. - 2016. - No. 4 (3). - R. 677-684.

95. Halbert, C. (2016) Long-term outcomes of patients with common bile duct injury following laparoscopic cholecystectomy. Surgical Endoscopy. 40. - R. 73-78.

96. Hirao, M. (2013) Roux-en-Y vs Billroth reconstruction after distal gastrectomy, WJG. 21. - P. 278-285.

97. Hogan, N.M. (2016) Iatrogenic common bile duct injuries: Increasing complexity in the laparoscopic era: A prospective cohort study, International Journal of Surgery. No. 33. -P.51156.

98. Hoya, Y. The advantages and disadvantages of a Roux-en-Y reconstruction after a distal gastrectomy for gastric cancer / Y. Hoya, N. Mitsumori, K. Yanaga // Surg. Today. --2009. - R. 647-651.

99. Hunt R., Armstrong D., Katelaris P. et al. (2015) Global perspectiv on gas-troesophageal reflux disease World Gastroenterology Organization. Wisconsin. USA. 2015.37 p. URL: http: //www.worldgastroenterology. org / guidelines / global-guidelines / gastroesophageal-reflux-disease / gastroesophageal-reflux-disease-english (accessed 07/18/2018).

100. Ishizuka, M. (2014) Prognostic nutritional index is associated with survival after total gastrectomy for patients with gastric cancer, Anticancer Res. No. 34. - R. 4223-4229.

101. Jo, J.H. (2017) Best options for preoperative biliary drainage in patients with Klatskin tumors, Surg Endosc. No. 31 (1). - R. 422429.

102. Kalil, A. (2017) Septic Shock, Medsscape. No. 1. - T. 1. - P. 35.

103. Kim, S.Y. (2018) Age 80 years and over is not associated with increased morbidity and mortality following pancreaticoduodenectomy, ANZ J Surg. No. 88 (5). - R. 445-450.

104. Kohn, G. P. (2013) Guidelines for the management of hiatal hernia. Society of American Gastrointestinal and Endoscopic Surgeons CA, $42 \mathrm{p}$.

105. Kohn, J. (2018) Characterization of common bile duct injury after laparoscopic. cholecystectomy in a high-volume hospital system, Surgical Endoscopy. 32 (3). - R. 1184-1191.

106. Loewy, R. (1996) Methode des greffes peritoneales / R Lo, S. S. Relationship between age and clinical characteristics of patients with gastric cancer, J. Gastroenterol Hepatol. -11. 6. - P. 511514.

107. Marco, B. (2001) Early postoperative enteral nutrition improves gut oxygenation and reduces costs compared with total parenteral nutrition, Crit. Care Med. 29. - P. 242-248.
108. Mathias, J. R. (1985) Nausea vomiting and abdominal pain after Roux-en-Y anastomosis: motility of the jejunal limb, Gastroenterology.188. - No. 6. - P. 101-107.

109. Moon, D.H. (2017) Clinical outcomes of video-assisted thoracoscopic surgery esophagectomy for esophageal cancer: a propensity score-matched analysis, J. Thorac. Dis. 9 (9). - P. 3005-3012.

110. Namikawa, T. (2011) Double tract reconstruction after distal gastrectomy for gastric cancer is effective in reducing reflux esophagitis and remnant gastritis with duodenal passage preservation, Langenbecks Arch. Surg. 396. - R. 769-776.

111. Nicola, W. (2003) Nutrition support to patients undergoing gastrointestinal surgery, Nutr. J. 2. - P. 1-5.

112. Nunobe, S. (2007) Billroth 1 versus Roux-en-Y reconstructions: a quality-of-life survey at 5 years, Int. J. Clin. Oncol. 12. - P. 433-439.

113. Oh CH. (2016) Percutaneous Transhepatic Cholangioscopy in Bilioenteric Anastomosis Stricture, Clin Endosc. 49. - P. 530 532.

114. Rainio, M. (2018) Endoscopic therapy of biliary injury after cholecystectomy, Digestive Diseases and Ssciences. 63 (2). - R. 474-480.

115. Rystedt, J. (2016) Bile duct injuries associated with 55.134 cholecystectomies: treatment and outcome from a national perspective, No. 40. - R. 73-80. World Journal of Surgery

116. Robkle, M. (1979) Bille in duced chronic gastric ul $\neg$ cer in swine with excised oxyntic hand area. Scand. J. Gastroent. 14 (5). - R. 521-528.

117. Roman, L.D. (2016) Vozmozhnosti hirurgicheskogo lechenij a oslozhnjonnyh form mestnorasprostranjonnogo raka grudnogo otdela pishhevoda, Preventive and clinical medicine. 3. S. $67-$ 71.

118. Saarinen, T. (2017) Bile reflux scintigraphy aftermini-gastric bypass, Obes. Surg. 27. 208. - P. 2083-2089.

119. Salama, T. M. S. (2017) Incidence of biliary reflux esophagitis after Laparoscopic omega loop gastric bypass in morbidly obese patients, J. Laparoendosc. Adv. Surg. Tech. A. 27(6). - P. 18-22.

120. Shamali, A. et al. (2017) Elderly patients have similar short term outcomes and five-year survival compared to younger patients after pancreaticoduodenectomy, Int J Surg Lond Engl. 45. - P. 138-143.

121. Shoda, J. (2015) Life-style and biliary tract cancer, Nihon Rinsho. 73 (Suppl 3). - R. 814-818.

122. Sylvia, van der Horst Robot-assisted minimally invasive thoraco-laparoscopic esophagectomy for esophageal cancer in the upper mediastinum / Sylvia van der et al. // Journal of Thoracic Disease. - 2017. - Vol. 9. - (Suppl 8). - P. 834-842.

123. Tanaka, S. (2011) Clinical outcomes of Roux-en-Y and Billroth I reconstruction after a distal gastrectomy for gastric cancer: What is the optimal reconstructive procedure? Hepatogastroenterol. 58 (105). - R. 257-62.

124. Thompson, S. A. (1945) The use of free omental grafts in the thorax. An experimental study, Am. J. Surg. 70. - P. 227-231.

125. Tolone, S. (2016) Effects of omega-loop bypass on esophagogastric junction function, Surg. Obes. Relat. Dis. 12. 6. - P. 62-69.

126. Van Hoeij, F.B. (2016) Clinical Application of Esophageal Highresolution Manometry in the Diagnosis of Esophageal Motility Disorders / F.B. Van ho 
